\title{
Estimation of the Parameters of the Exact Extreme Value Distribution
}

\author{
Dr. Neamat Qutb ${ }^{1}$, Dr. Aisha Fayomi ${ }^{2}$, Ohoud Al-Beladi ${ }^{3}$ \\ ${ }^{1,2,3}$ (Department Of Statistics, Faculty Of Science / King Abdulaziz University, Saudi Arabia.)
}

\begin{abstract}
Exact extreme value distribution is one of the most important compound distributions which is based on the theory of the maximum of random variable of random numbers. This distribution uses partial duration series (PDS) data to analyze extreme hydrological. This distribution is presented with its properties and graphical representations. Moments (MOM), maximum likelihood (ML) and Bayesian - based on noninformative and informative prior-methods are used to estimate the unknown parameters of the distribution. Markov Chain Monte Carlo (MCMC) technique is used to compute the Bayesian estimates. The simulation is performed to investigate and compare between the estimators with different sizes and a set of the parameter's values. In the sense of the mean squared error (MSE), the results showed that Bayesian -based on informative prior-method is the best estimation method.
\end{abstract}

Keywords: Exact extreme value distribution, maximum likelihood, Bayesian estimation, MCMC.

\section{Introduction}

Compound distributions can be useful in various fields such as business failures, reliability and life testing, risk theory, queuing theory, economic theory, extreme value theory, radar theory and also for purely theoretical considerations. In many of these cases the compound distribution or some special cases of it are good representations for the explanation of the underlying stochastic phenomena. Also, from the fact that some of the parameters of the simple distribution could themselves be random variables, it is quite reasonable to assume that the compound distribution would be suitable in many applications.

Compound distributions which is based on the theory of the maximum of random variable of random numbers back to 1970 when Todorovic presented the theory of exact extreme value. This compound model uses partial duration series PDF- Peak over Threshold (POT)- which consist of flood peaks exceeding some threshold value as an alternative analytical tool for Maxima's annual discharge method which consist of maximum flow rates from each year within the observation period to analyze extreme flood. The theoretical basis for development of the POT method was set by work of Todorovic [1,2]. The model represents the stochastic nature of the number and magnitude of the exceedances by Poisson and exponential distributions respectively.[3] studied some properties of the compound exponential - Poisson distribution they also estimated its parameter by maximum likelihood method and used the estimators in goodness of fit test of the model to data from Aswan station on the Nile River. As an alternative to Poisson distribution for flood count, negative binomial distribution was proposed by [4]. [5] found that the Poisson distribution was better than the negative binomial distribution in cases when the difference between the mean and the variance of the annual number of exceedences was small. [6] Compared between the PDS method and the annual maximum(AM) method for flood frequency analysis for data from the Litija 1 gauging station on the Sava River in Slovenia. The POT method gave best results than the AM method. The POT model used the exponential and Pareto distributions for modelling the magnitudes of exceedences, and the Poisson, binomial and negative binomial distributions for the annual number of events above the threshold. Four tests were used to check the adequacy of the Poisson and exponential distributions. For modelling the annual number of exceedences above the threshold, the Poisson distribution gave best results than the binomial distribution.

The main purpose of this paper is to study the properties of the exact extreme value model, and estimate its parameters.

This paper is organized as follows: Section 1, introduction to Exact extreme value distribution. Section 2 introduces the distribution of the extremes of random variables of random numbers. Section 3 provides the theoretical considerations of the model. Section 4 illustrates the statistical properties of the model. Section 5 estimation of the unknown parameters of the distribution using MOM, ML and Bayesian methods. A simulation study is conducted in Section 6. The conclusions are shown in Section 7. 


\section{Distribution of Extremes of Random Variables of Random Numbers}

[1] presented an approach to analyze extreme values of random numbers of occurring phenomena. He defined a sequence of observations $\xi_{v}, v=1,2, \ldots$ with number of occurrence $\eta(t)$, and the probability function of $\eta(t)$, as $p\{\eta(t)=v\}=p\left(E_{v}^{t}\right)$, giving an attention to the two variables:

$$
\begin{gathered}
X(t)=\max \left(\xi_{v}, v=1,2, \ldots\right), \text { and } \\
Z(t)=\min \left(\xi_{v}, v=1,2, \ldots\right) .
\end{gathered}
$$

He derived the distribution function for $X(t)$ and $Z(t)$ denoted by $F(x)$ and $F(z)$ respectively, as

$$
\begin{gathered}
F(x)=\sum_{k=0}^{\infty} p\left[\bigcap_{v=0}^{k}\left\{\xi_{v} \leq x\right\} \bigcap E_{k}^{t}\right], \\
F(\mathrm{z})=1-\sum_{k=1}^{\infty} p\left[\bigcap_{v=1}^{k}\left\{\xi_{v}>x\right\} \bigcap E_{k}^{t}\right] .
\end{gathered}
$$

Suppose that $\xi_{v}$ is a sequence of independent random variables with the common distribution function $H(x)$ and $\eta(t)$ independent of $\left\{\xi_{v}\right\}$ then (3) and (4) become:

$$
\begin{gathered}
F(x)=\sum_{k=0}^{\infty}[H(x)]^{k} p\left(E_{k}^{t}\right), \\
F(z)=1-\sum_{k=1}^{\infty}[1-H(z)]^{k} p\left(\mathrm{E}_{\mathrm{k}}^{\mathrm{t}}\right) .
\end{gathered}
$$

\section{Theoretical Considerations}

According to exact extreme value theory presented in Section 2, [2] developed a general stochastic model to describe and predict behavior of floods. The theory of this model is presented as follows.

Consider a stream flow hydrograph, representing the instant flood peaks at a given station within an interval of time $[0, t]$. Let us consider only those peaks $Q_{V}, \mathrm{v}=1,2, \ldots, \mathrm{n}$ that exceed the base level $Q_{0}$. Let the magnitude of flood exceedances be defined as follows

$$
\xi_{v}=Q_{v}-Q_{0}, \xi>0
$$

According to the nature of flood phenomena, the number of flood exceedance $\eta(t)$, the magnitude of flood exceedances $\xi_{v}$ and the time of occurrence of flood exceedances $\tau_{v}$ in a given interval of time $[0, t]$ are random variables.

Unlike the asymptotic extreme value model, the $\eta(t)$ plays an important role in the exact extreme value model because the latter model considers both $\eta(t)$ and the $\xi_{v}$ simultaneously. The number of exceedances $\eta(t)$ in $[0, t]$ is defined as

$$
\eta(t)=\sup (\mathrm{v}), \tau_{\mathrm{v}} \leq t .
$$

By definition, $\eta(t)=0,1,2, \ldots$ for all $t \geq 0$ and $\eta(t) \leq \eta(t+\Delta t)$ for $t \geq 0$ and $\Delta t>0$; this means, $\eta(t)$ is a non-decreasing function of $t$. In the event that there are exactly v exceedances occurring in $[0, t]$, let

$$
E_{v}^{t}=\{\eta(\mathrm{t})=\mathrm{v}\} \text {. }
$$

In which $\mathrm{v}$ is a particular numerical value of the random variable $\eta(t)$. Let $\alpha$ stand for the expected value of $\eta(t)$, then

$$
\alpha=\sum_{\mathrm{v}=1}^{\infty} \mathrm{v} p\left(\mathrm{E}_{\mathrm{v}}^{\mathrm{t}}\right)
$$


In the case of flood analysis, the random variable of the largest exceedance $X(t)$, among the set of all exceedances $\xi_{v}$ within a specific time interval $[0, t]$ plays an important role, $X(t)$ is defined as

$$
X(t)=\sup \left(\xi_{\mathrm{v}}\right), \tau_{\mathrm{v}} \leq t .
$$

By definition, $X(t) \leq X(t+\Delta t)$ for $t \geq 0$ and $\Delta t>0$; this means that $X(t)$ is a non-decreasing stochastic process.

Denote by $F(x)$ the distribution function of $X(t)$, i.e

$$
F(x)=P\{\mathrm{X}(t) \leq x\}, \mathrm{t} \geq 0, \mathrm{x} \geq 0 .
$$

[1]derived an expression for $F(x)$, on the basis of mathematical expectation of the conditional probability, $P\{X(t) \leq x \mid \eta(t)\}$ as

$$
\begin{aligned}
F(x) & =\mathrm{E}[P\{X(t) \leq x \mid \eta(t)\}] \\
& =\mathrm{E}\left[P\left\{\sup \left(\xi_{v}\right) \leq x \mid \eta(t)\right\}\right], \tau_{\mathrm{v}} \leq t \\
& =\sum_{\mathrm{n}=0}^{\infty} P\left[\left\{\sup \left(\xi_{v}\right) \leq x \mid \eta(t)\right\} \bigcap \mathrm{E}_{\mathrm{n}}^{\mathrm{t}}\right], \tau_{\mathrm{v}} \leq t, 0<\mathrm{v} \leq n . \\
& =\sum_{\mathrm{n}=0}^{\infty} P\left\{\bigcap_{v=0}^{n}\left(\xi_{v} \leq x\right) \bigcap \mathrm{E}_{\mathrm{n}}^{\mathrm{t}}\right\} \\
& =P\left(E_{0}^{t}\right)+\sum_{n=1}^{\infty} P\left\{\bigcap_{v=1}^{n}\left(\xi_{v} \leq x\right) \bigcap E_{n}^{t}\right\} .
\end{aligned}
$$

Equation (13) describes the most general form of Todorovic's exact extreme value stochastic flood model for the distribution function of largest exceedances $[F(x)=P\{X(t) \leq x\}]$ in a specific time period $[0, t]$. Equation (13) is difficult to be solved directly unless one determines the probability $P\left\{\bigcap_{v=0}^{n}\left(\xi_{v} \leq x\right) \bigcap E_{n}^{t}\right\}$. Therefore, it is necessary to consider a particular form of equation (13) in which the $\xi_{v}, v=1,2, \ldots$ occurring in $[0, t]$ are identical independent random variables, with the common distribution function $H(x)$ and the random sequences $\xi_{v}$ and $\tau_{v}$ are stochastically independent for all v. Under these assumptions, equation (13) simplifies to

$$
\begin{aligned}
F(x) & =P\left(E_{0}^{t}\right)+\sum_{n=1}^{\infty}\left\{P\left(\xi_{v} \leq x\right)\right\}^{n} P\left(E_{n}^{t}\right) \\
& =P\left(E_{0}^{t}\right)+\sum_{n=1}^{\infty}\{H(x)\}^{n} P\left(E_{n}^{t}\right),
\end{aligned}
$$

where $H(x)$ is the distribution function of the exceedances and $P\left(E_{0}^{t}\right)$ is interpreted as the probability that there will be no exceedances $(v=0)$ in a given time interval $[0, t]$.

In the flood context, $\eta$ is a time dependent Poisson process. Suppose that $\eta$ is distributed as Poisson with parameter $\alpha$, and its probability function is given by

$$
P\left(E_{v}^{t}\right)=P(\eta=\mathrm{v})=\frac{\exp (-\alpha) \alpha^{v}}{v !}, v=0,1,2, \ldots
$$

The exponential distribution has been used frequently in fitting frequency distributions to magnitudes of exceedances $\xi_{v}$. This distribution is applicable to magnitudes of exceedances evaluated for a range of truncation levels. The probability density function ( PDF ) and the cumulative distribution function ( CDF ) of exponentially distributed random variables $\xi_{v}$ can be expressed, respectively, as 


$$
\begin{gathered}
h(x)=\frac{1}{\beta} \exp \left(-\frac{x}{\beta}\right), x \geq 0, \beta>0 . \\
H(x)=P\left(\xi_{v} \leq x\right)=1-\exp \left(-\frac{x}{\beta}\right) .
\end{gathered}
$$

By substituting equations (15) and (17) in (14) we get the existing form of the exact extreme values model as

$$
\begin{aligned}
F(x) & =p\left(E_{0}^{t}\right)+\sum_{n=1}^{\infty}\left\{1-\exp \left(-\frac{x}{\beta}\right)\right\}^{n} \frac{\exp (-\alpha) \alpha^{n}}{\mathrm{n} !} \\
& =\exp (-\alpha)+\exp (-\alpha) \sum_{n=1}^{\infty} \frac{1}{\mathrm{n} !}\left\{\alpha\left(1-\exp \left(-\frac{x}{\beta}\right)\right)\right\}^{n}
\end{aligned}
$$

which reduces to

$$
F(x)=\exp \left[-\alpha \exp \left(-\frac{x}{\beta}\right)\right] .
$$

Differentiating the CDF (19) of the process with respect to $\mathrm{x}$ the PDF is obtained as

$$
f(x)=\frac{\alpha}{\beta} \exp \left(-\frac{x}{\beta}\right) \exp \left[-\alpha \exp \left(-\frac{x}{\beta}\right)\right],-\infty<x<\infty ; \alpha, \beta>0 \text {. }
$$

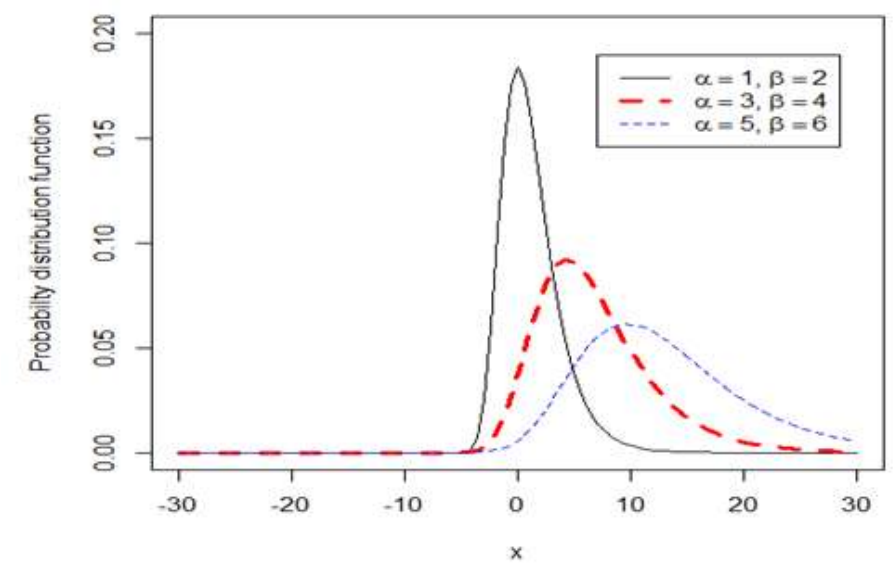

Figure 1: The PDF of the exact extreme value model

It is clear from the above Fig. 1 that the PDF of the exact extreme value model can take different shapes

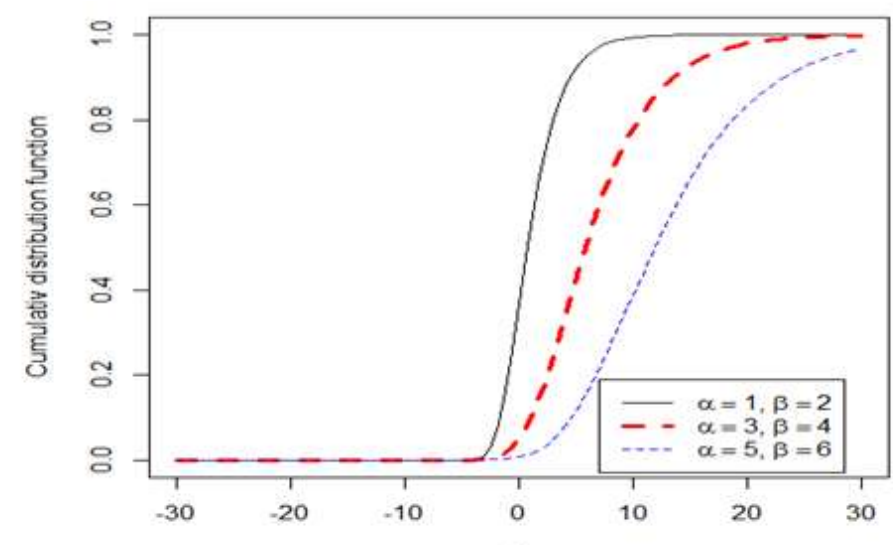

Figure 2: The CDF of the exact extreme value model 


\section{Statistical Properties}

In this section we present some properties of the exact extreme value model.

\subsection{The reliability and hazard rate functions}

The reliability function (RF) and the hazard rate function(HRF) for the exact extreme value model are given respectively by

$$
\begin{gathered}
R(x)=1-F(x)=1-\exp \left[-\alpha \exp \left(-\frac{x}{\beta}\right)\right] . \\
h(x)=\frac{f(x)}{R(x)}=\frac{\frac{\alpha}{\beta} \exp \left(-\frac{x}{\beta}\right) \exp \left[-\alpha \exp \left(-\frac{x}{\beta}\right)\right]}{1-\exp \left[-\alpha \exp \left(-\frac{x}{\beta}\right)\right]} .
\end{gathered}
$$

From Fig. 3 it is clear that the hazard rate is an increasing function

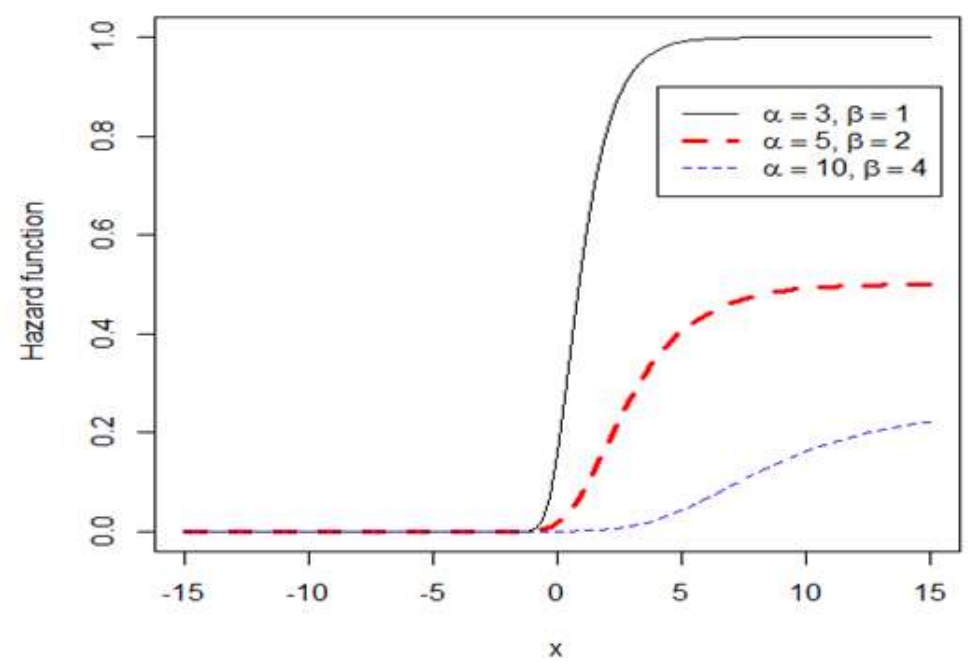

Figure 3: The HRF of the exact extreme value model

\subsection{The cumulative hazard function}

The cumulative hazard function $H(x)$ is

$$
H(x)=\int_{-\infty}^{x} h(x) d x=-\left[\ln \left(1-\exp \left(-\alpha \exp \left(-\frac{x}{\beta}\right)\right)\right)\right] .
$$

4.3 The Quantile function

The quantile function corresponding to the distribution in equation (19) is given by

$$
x_{q}=-\beta \ln \left[-\frac{1}{\alpha}(\ln q)\right], 0<\mathrm{q}<1 .
$$

4.4 The $r^{\text {th }}$ moment and moment generating function

The moment generating function of the exact extreme value model is given by

$$
\begin{aligned}
M(t) & =E\left(e^{t \mathrm{x}}\right)=\int_{-\infty}^{\infty} e^{t x} f(x) d x \\
& =\alpha^{\beta t} \Gamma(1-\beta t) .
\end{aligned}
$$

where $\Gamma($.) denotes the gamma function.

Finding the $r^{t h}$ moment by differentiating $M(t)$ with respect to $\mathrm{t}$ and putting $\mathrm{t}=0$, one obtains the $r^{\text {th }}$ moment about zero of the density function (20) as 


$$
M_{r}=E\left(x^{r}\right)=\frac{\partial^{r}\left[\alpha^{\beta \mathrm{t}} \Gamma(1-\beta t)\right]}{\partial t^{r}} .
$$

4.5 The mean, variance, mode and median

The mean, variance, mode and median of the exact extreme value model are given respectively by

$$
\begin{gathered}
E(X) \approx \beta \gamma+\beta \ln (\alpha) . \\
V(X) \approx \beta^{2} \frac{\pi^{2}}{6} . \\
\text { Mode }=\beta \ln (\alpha) . \\
\text { Median }=\beta[\ln (\alpha)+0.3665] \\
=\text { mode }+0.3665 \beta
\end{gathered}
$$

where $\gamma$ is the Euler-Mascheroni constant

\subsection{The skewness and kurtosis coefficients}

The skewness and kurtosis are given respectively by

$$
\gamma_{1}=\frac{M_{3}}{M_{2}^{3 / 2}}=\frac{2 \beta^{3} \xi(3)}{\left(\frac{\pi^{2} \beta^{2}}{6}\right)^{3 / 2}} \approx 1.4 .
$$

Where $\xi(3)=1.202$ is A Apéry's constant.

Exact extreme value distribution is positively skewed distribution.

$$
\gamma_{2}=\frac{M_{4}}{M_{2}^{2}}=\frac{\beta^{4}\left(\frac{\pi^{4}}{12}+\frac{\pi^{4}}{15}\right)}{\left(\frac{\pi^{2} \beta^{2}}{6}\right)^{2}} \approx 5.4 .
$$

Exact extreme value distribution is leptokurtic distribution.

\section{Estimation methods}

In this section, MOM, ML and Bayesian methods is used to estimate the unknown parameters $\alpha$ and $\beta$ of the exact extreme value model. Bayesian method is conducted using non-informative prior distributions and also informative prior distributions is used. The Bayes estimates under squared error loss functions is obtained.

\subsection{The method of moments}

Moment estimators of the shape parameter $\alpha$ and the scale parameter $\beta$ of the exact extreme value distribution are found by equating the sample moments to the corresponding theoretical moments. In other words, they are the solutions of the following equalities

$$
\bar{X}=\beta \gamma+\beta \ln (\alpha) \text { and } \mathrm{S}^{2}=\frac{\pi^{2}}{6} \beta^{2} .
$$

Moment estimators of $\alpha$ and $\beta$ are then obtained as

$$
\widehat{\beta}=\sqrt{6} \frac{S}{\pi} \text { and } \widehat{\alpha}=\exp \left(\frac{\overline{\mathrm{X}}}{\widehat{\beta}}-\gamma\right) \text {. }
$$

\subsection{Maximum likelihood estimation}

Suppose that $\underline{X}\left(X_{1}, X_{2}, \ldots X_{n}\right)$ is a random sample of size $\mathrm{n}$ from, exact extreme value distribution then the $\log$-likelihood function is given by 


$$
\log L=n \log (\alpha)-n \log (\beta)-\frac{1}{\beta} \sum_{i=1}^{n} x_{i}-\alpha \sum_{i=1}^{n} \exp \left(-\frac{x_{i}}{\beta}\right) .
$$

Differentiating (35) with respect to $\alpha$ and $\beta$ respectively and equating the resulting derivatives to zero, we get

$$
\begin{aligned}
& \frac{\partial \log L}{\partial \widehat{\alpha}}=\frac{n}{\widehat{\alpha}}-\sum_{i=1}^{n} \exp \left[-\frac{x_{i}}{\widehat{\beta}}\right]=0 \\
& \frac{\partial \log L}{\partial \widehat{\beta}}=\frac{-n}{\widehat{\beta}}+\frac{\sum_{i=1}^{n} x_{i}}{\widehat{\beta}^{2}}-\frac{\widehat{\alpha}}{\widehat{\beta}^{2}} \sum_{i=1}^{n} x_{i} \exp \left[-\frac{x_{i}}{\widehat{\beta}}\right]=0
\end{aligned}
$$

To obtain the ML estimates of the shape parameter $\alpha$ and the scale parameter $\beta$, numerical calculations are required to find the solution of the system of the nonlinear equation (36).

\subsubsection{Bayesian estimation using non-informative prior}

Suppose we assume that the unknown parameters $\alpha$ and $\beta$ have the following independent prior distributions

$$
\alpha \sim \text { uniform }(a, b), \beta \sim \text { uniform }(a, b) \text {. }
$$

Then, the joint posterior probability can be written as:

$$
\pi^{\bullet}(\alpha, \beta \mid \underline{x})=A_{1} \frac{\alpha^{n}}{B^{n}} \exp \left(\sum_{i=1}^{n}-\frac{x_{i}}{\beta}\right) \exp \left[-\alpha \sum_{i=1}^{n} \exp \left(-\frac{x_{i}}{\beta}\right)\right] \times \pi(\alpha, \beta),
$$

where $\pi(\alpha, \beta)$ is the joint prior distribution of the parameters, and $A_{1}$ is the normalizing constant. Bayesian estimators under squared error loss function can be obtained by taking the mean of the equation (37). MCMC technique is used to find the Bayesian estimates of $\alpha$ and $\beta$ numerically.

\subsubsection{Bayesian estimation using informative prior}

Let each of $\alpha$ and $\beta$ are independent random variables and follow one parameter inverted gamma $\left(k_{i}\right)$ distribution, $i=1,2$ respectively, then the prior distribution for each parameters can be written as follows:

$$
\begin{aligned}
& \pi(\alpha)=\frac{1}{\Gamma\left(k_{1}\right)} \alpha^{-\left(k_{1}+1\right)} e^{-\frac{1}{\alpha}}, \alpha>0 . \\
& \pi(\beta)=\frac{1}{\Gamma\left(k_{2}\right)} \beta^{-\left(k_{2}+1\right)} e^{-\frac{1}{\beta}}, \beta>0 .
\end{aligned}
$$

Then, the joint posterior probability can be written as:

$$
\pi^{\bullet}(\alpha, \beta \mid \underline{x})=A_{2} \frac{\alpha^{n}}{\beta^{n}} \exp \left(-\sum_{i=1}^{n} \frac{x_{i}}{\beta}\right) \exp \left[-\alpha \sum_{i=1}^{n} \exp \left(-\frac{x_{i}}{\beta}\right)\right] . \pi(\alpha, \beta) .
$$

where $\pi(\alpha, \beta)$ is the joint prior distribution of the parameters, and $A_{2}$ is the normalizing constant. Bayesian estimators under squared error loss function can be obtained by taking the mean of the equation (40). MCMC technique is used to find the Bayesian estimates of $\alpha$ and $\beta$ numerically.

\section{Simulation Study}

In this section, simulation study and results are presented. Simulation study have been performed to obtain the estimates presented in section (5). This simulation was performed for different sample size $n=10,30$, 100 and a set of the parameter's. Each sample size is repeated 1000 times. For 1000 replications, the estimated MSE of the estimates are calculated for each method. The results are shown in Table 1. 
Table 1: MOM, ML and Bayesian estimates with their (MSE) under exact extreme value distribution

\begin{tabular}{|c|c|c|c|c|c|c|c|c|c|c|}
\hline & \multirow{2}{*}{\multicolumn{2}{|c|}{ Parameters }} & \multirow{2}{*}{\multicolumn{2}{|c|}{ MOM }} & \multirow{2}{*}{\multicolumn{2}{|c|}{ ML }} & \multicolumn{4}{|c|}{ Bayesian } \\
\hline & & & & & & & \multicolumn{2}{|c|}{ non-informative } & \multicolumn{2}{|c|}{ informative } \\
\hline & $\alpha$ & $\beta$ & $\hat{\alpha}$ & $\widehat{\beta}$ & $\hat{\alpha}$ & $\widehat{\beta}$ & $\hat{\alpha}$ & $\widehat{\beta}$ & $\hat{\alpha}$ & $\widehat{\beta}$ \\
\hline \multirow{9}{*}{10} & \multirow{3}{*}{0.25} & 0.25 & $\begin{array}{c}0.2498 \\
(0.0212)\end{array}$ & $\begin{array}{c}0.2377 \\
(0.0052)\end{array}$ & $\begin{array}{c}0.2505 \\
(0.0192)\end{array}$ & $\begin{array}{c}0.2345 \\
(0.0034)\end{array}$ & $\begin{array}{c}0.3765 \\
(0.0375)\end{array}$ & $\begin{array}{c}0.3023 \\
(0.0077)\end{array}$ & $\begin{array}{c}0.3451 \\
(0.0157)\end{array}$ & $\begin{array}{c}0.2809 \\
(0.0027)\end{array}$ \\
\hline & & 0.50 & $\begin{array}{c}0.2498 \\
(0.0212) \\
\end{array}$ & $\begin{array}{c}0.4753 \\
(0.0207) \\
\end{array}$ & $\begin{array}{c}0.2505 \\
(0.0192) \\
\end{array}$ & $\begin{array}{c}0.4691 \\
(0.0135) \\
\end{array}$ & $\begin{array}{c}0.3765 \\
(0.0375) \\
\end{array}$ & $\begin{array}{c}0.6048 \\
(0.0308) \\
\end{array}$ & $\begin{array}{c}0.3168 \\
(0.0106) \\
\end{array}$ & $\begin{array}{c}0.5217 \\
(0.0073) \\
\end{array}$ \\
\hline & & 0.75 & $\begin{array}{c}0.2498 \\
(0.0212) \\
\end{array}$ & $\begin{array}{c}0.7130 \\
(0.0465) \\
\end{array}$ & $\begin{array}{c}0.2505 \\
(0.0192) \\
\end{array}$ & $\begin{array}{c}0.7036 \\
(0.0304) \\
\end{array}$ & $\begin{array}{c}0.3764 \\
(0.0374) \\
\end{array}$ & $\begin{array}{c}0.9070 \\
(0.0691) \\
\end{array}$ & $\begin{array}{c}0.3076 \\
(0.0092) \\
\end{array}$ & $\begin{array}{c}0.7638 \\
(0.0154) \\
\end{array}$ \\
\hline & \multirow{3}{*}{0.50} & 0.25 & $\begin{array}{c}0.5136 \\
(0.0608)\end{array}$ & $\begin{array}{c}0.2377 \\
(0.0052)\end{array}$ & $\begin{array}{c}0.5115 \\
(0.0574)\end{array}$ & $\begin{array}{c}0.2319 \\
(0.0038)\end{array}$ & $\begin{array}{c}0.6480 \\
(0.0795)\end{array}$ & $\begin{array}{c}0.2886 \\
(0.0064)\end{array}$ & $\begin{array}{c}0.5311 \\
(0.0286)\end{array}$ & $\begin{array}{c}0.2534 \\
(0.0021)\end{array}$ \\
\hline & & 0.50 & $\begin{array}{c}0.5136 \\
(0.0608) \\
\end{array}$ & $\begin{array}{c}0.4753 \\
(0.0207) \\
\end{array}$ & $\begin{array}{c}0.5114 \\
(0.0575) \\
\end{array}$ & $\begin{array}{c}0.4638 \\
(0.0153) \\
\end{array}$ & $\begin{array}{c}0.6480 \\
(0.0795) \\
\end{array}$ & $\begin{array}{c}0.5772 \\
(0.0257) \\
\end{array}$ & $\begin{array}{c}0.4902 \\
(0.0289) \\
\end{array}$ & $\begin{array}{c}0.4593 \\
(0.0100) \\
\end{array}$ \\
\hline & & 0.75 & $\begin{array}{c}0.5136 \\
(0.0608)\end{array}$ & $\begin{array}{c}0.7130 \\
(0.0465)\end{array}$ & $\begin{array}{c}0.5114 \\
(0.0575)\end{array}$ & $\begin{array}{c}0.6957 \\
(0.0344)\end{array}$ & $\begin{array}{c}0.6475 \\
(0.0793)\end{array}$ & $\begin{array}{c}0.8657 \\
(0.0579)\end{array}$ & $\begin{array}{c}0.4759 \\
(0.0298)\end{array}$ & $\begin{array}{c}0.6664 \\
(0.0257)\end{array}$ \\
\hline & \multirow{3}{*}{0.75} & 0.25 & $\begin{array}{c}0.8009 \\
(0.1382)\end{array}$ & $\begin{array}{c}0.2377 \\
(0.0052) \\
\end{array}$ & $\begin{array}{c}0.7988 \\
(0.1226) \\
\end{array}$ & $\begin{array}{c}0.2318 \\
(0.0038) \\
\end{array}$ & $\begin{array}{c}0.9339 \\
(0.1887) \\
\end{array}$ & $\begin{array}{c}0.2807 \\
(0.0059) \\
\end{array}$ & $\begin{array}{c}0.7446 \\
(0.0680)\end{array}$ & $\begin{array}{c}0.2471 \\
(0.0023)\end{array}$ \\
\hline & & 0.50 & $\begin{array}{c}0.8009 \\
(0.1382) \\
\end{array}$ & $\begin{array}{c}0.4753 \\
(0.0207) \\
\end{array}$ & $\begin{array}{c}0.7986 \\
(0.1227) \\
\end{array}$ & $\begin{array}{c}0.4636 \\
(0.0154)\end{array}$ & $\begin{array}{c}0.9339 \\
(0.1890) \\
\end{array}$ & $\begin{array}{c}0.5615 \\
(0.0235) \\
\end{array}$ & $\begin{array}{c}0.7048 \\
(0.0850)\end{array}$ & $\begin{array}{c}0.4423 \\
(0.0126) \\
\end{array}$ \\
\hline & & 0.75 & $\begin{array}{c}0.8009 \\
(0.1382) \\
\end{array}$ & $\begin{array}{c}0.7130 \\
(0.0465) \\
\end{array}$ & $\begin{array}{c}0.7986 \\
(0.1227) \\
\end{array}$ & $\begin{array}{c}0.6954 \\
(0.0347) \\
\end{array}$ & $\begin{array}{c}0.9336 \\
(0.1876) \\
\end{array}$ & $\begin{array}{c}0.8425 \\
(0.0531) \\
\end{array}$ & $\begin{array}{c}0.6900 \\
(0.0929) \\
\end{array}$ & $\begin{array}{c}0.6385 \\
(0.0332) \\
\end{array}$ \\
\hline \multirow{9}{*}{30} & \multirow{3}{*}{0.25} & 0.25 & $\begin{array}{c}0.2464 \\
(0.0070) \\
\end{array}$ & $\begin{array}{c}0.2457 \\
(0.0022) \\
\end{array}$ & $\begin{array}{c}0.2449 \\
(0.0061) \\
\end{array}$ & $\begin{array}{c}0.2427 \\
(0.0013) \\
\end{array}$ & $\begin{array}{c}0.2910 \\
(0.0085) \\
\end{array}$ & $\begin{array}{c}0.2644 \\
(0.0016) \\
\end{array}$ & $\begin{array}{c}0.2929 \\
(0.0055) \\
\end{array}$ & $\begin{array}{c}0.2636 \\
(0.0010) \\
\end{array}$ \\
\hline & & 0.50 & $\begin{array}{c}0.2464 \\
(0.0070) \\
\end{array}$ & $\begin{array}{c}0.4914 \\
(0.0087) \\
\end{array}$ & $\begin{array}{c}0.2449 \\
(0.0061) \\
\end{array}$ & $\begin{array}{c}0.4854 \\
(0.0052) \\
\end{array}$ & $\begin{array}{c}0.2910 \\
(0.0085) \\
\end{array}$ & $\begin{array}{c}0.5289 \\
(0.0064) \\
\end{array}$ & $\begin{array}{c}0.2797 \\
(0.0044) \\
\end{array}$ & $\begin{array}{c}0.5109 \\
(0.0034) \\
\end{array}$ \\
\hline & & 0.75 & $\begin{array}{c}0.2464 \\
(0.0070)\end{array}$ & $\begin{array}{c}0.7371 \\
(0.0196)\end{array}$ & $\begin{array}{c}0.2449 \\
(0.0061)\end{array}$ & $\begin{array}{c}0.7281 \\
(0.0118)\end{array}$ & $\begin{array}{c}0.2909 \\
(0.0084)\end{array}$ & $\begin{array}{c}0.7933 \\
(0.0143)\end{array}$ & $\begin{array}{c}0.2752 \\
(0.0041)\end{array}$ & $\begin{array}{c}0.7584 \\
(0.0074)\end{array}$ \\
\hline & \multirow{3}{*}{0.50} & 0.25 & $\begin{array}{c}0.4972 \\
(0.0157)\end{array}$ & $\begin{array}{c}0.2457 \\
(0.0022)\end{array}$ & $\begin{array}{c}0.4968 \\
(0.0154)\end{array}$ & $\begin{array}{c}0.2426 \\
(0.0013)\end{array}$ & $\begin{array}{c}0.5485 \\
(0.0183)\end{array}$ & $\begin{array}{c}0.2606 \\
(0.0015)\end{array}$ & $\begin{array}{c}0.5071 \\
(0.0117)\end{array}$ & $\begin{array}{c}0.2495 \\
(0.0010)\end{array}$ \\
\hline & & 0.50 & $\begin{array}{c}0.4972 \\
(0.0157) \\
\end{array}$ & $\begin{array}{c}0.4914 \\
(0.0087) \\
\end{array}$ & $\begin{array}{c}0.4968 \\
(0.0154) \\
\end{array}$ & $\begin{array}{c}0.4852 \\
(0.0053) \\
\end{array}$ & $\begin{array}{c}0.5486 \\
(0.0183) \\
\end{array}$ & $\begin{array}{c}0.5212 \\
(0.0060) \\
\end{array}$ & $\begin{array}{c}0.4882 \\
(0.0119) \\
\end{array}$ & $\begin{array}{c}0.4805 \\
(0.0045) \\
\end{array}$ \\
\hline & & 0.75 & $\begin{array}{c}0.4972 \\
(0.0157)\end{array}$ & $\begin{array}{c}0.7371 \\
(0.0196) \\
\end{array}$ & $\begin{array}{c}0.4968 \\
(0.0154) \\
\end{array}$ & $\begin{array}{c}0.7279 \\
(0.0119) \\
\end{array}$ & $\begin{array}{c}0.5485 \\
(0.0183) \\
\end{array}$ & $\begin{array}{c}0.7818 \\
(0.0135) \\
\end{array}$ & $\begin{array}{c}0.4817 \\
(0.0121) \\
\end{array}$ & $\begin{array}{c}0.7118 \\
(0.0106) \\
\end{array}$ \\
\hline & \multirow{3}{*}{0.75} & 0.25 & $\begin{array}{c}0.7556 \\
(0.0282)\end{array}$ & $\begin{array}{c}0.2457 \\
(0.0022)\end{array}$ & $\begin{array}{c}0.7555 \\
(0.0277)\end{array}$ & $\begin{array}{c}0.2426 \\
(0.0013)\end{array}$ & $\begin{array}{c}0.8082 \\
(0.0317)\end{array}$ & $\begin{array}{c}0.2584 \\
(0.0015)\end{array}$ & $\begin{array}{c}0.7417 \\
(0.0234)\end{array}$ & $\begin{array}{c}0.2471 \\
(0.0011)\end{array}$ \\
\hline & & 0.50 & $\begin{array}{c}0.7556 \\
(0.0282)\end{array}$ & $\begin{array}{c}0.4914 \\
(0.0087)\end{array}$ & $\begin{array}{c}0.7555 \\
(0.0277)\end{array}$ & $\begin{array}{c}0.4852 \\
(0.0053)\end{array}$ & $\begin{array}{c}0.8081 \\
(0.0317)\end{array}$ & $\begin{array}{c}0.5167 \\
(0.0058)\end{array}$ & $\begin{array}{c}0.7225 \\
(0.0248)\end{array}$ & $\begin{array}{c}0.4749 \\
(0.0050)\end{array}$ \\
\hline & & 0.75 & $\begin{array}{c}0.7556 \\
(0.0282) \\
\end{array}$ & $\begin{array}{c}0.7371 \\
(0.0196) \\
\end{array}$ & $\begin{array}{c}0.7555 \\
(0.0277) \\
\end{array}$ & $\begin{array}{c}0.7279 \\
(0.0119) \\
\end{array}$ & $\begin{array}{c}0.8082 \\
(0.0317) \\
\end{array}$ & $\begin{array}{c}0.7751 \\
(0.0131) \\
\end{array}$ & $\begin{array}{c}0.7158 \\
(0.0255) \\
\end{array}$ & $\begin{array}{c}0.7029 \\
(0.0120) \\
\end{array}$ \\
\hline \multirow{9}{*}{100} & \multirow{3}{*}{0.25} & 0.25 & $\begin{array}{c}0.2508 \\
(0.0021) \\
\end{array}$ & $\begin{array}{c}0.2494 \\
(0.0006) \\
\end{array}$ & $\begin{array}{c}0.2497 \\
(0.0019) \\
\end{array}$ & $\begin{array}{c}0.2481 \\
(0.0004) \\
\end{array}$ & $\begin{array}{c}0.2642 \\
(0.0021) \\
\end{array}$ & $\begin{array}{c}0.2551 \\
(0.0004) \\
\end{array}$ & $\begin{array}{c}0.2664 \\
(0.0018) \\
\end{array}$ & $\begin{array}{c}0.2555 \\
(0.0003) \\
\end{array}$ \\
\hline & & 0.50 & $\begin{array}{c}0.2508 \\
(0.0021)\end{array}$ & $\begin{array}{c}0.4989 \\
(0.0025)\end{array}$ & $\begin{array}{c}0.2497 \\
(0.0019)\end{array}$ & $\begin{array}{c}0.4962 \\
(0.0015)\end{array}$ & $\begin{array}{c}0.2642 \\
(0.0021)\end{array}$ & $\begin{array}{c}0.5102 \\
(0.0016)\end{array}$ & $\begin{array}{c}0.2615 \\
(0.0016)\end{array}$ & $\begin{array}{c}0.5053 \\
(0.0013)\end{array}$ \\
\hline & & 0.75 & $\begin{array}{c}0.2508 \\
(0.0021) \\
\end{array}$ & $\begin{array}{c}0.7483 \\
(0.0055) \\
\end{array}$ & $\begin{array}{c}0.2497 \\
(0.0019) \\
\end{array}$ & $\begin{array}{c}0.7443 \\
(0.0033) \\
\end{array}$ & $\begin{array}{c}0.2642 \\
(0.0021) \\
\end{array}$ & $\begin{array}{c}0.7654 \\
(0.0036) \\
\end{array}$ & $\begin{array}{c}0.2599 \\
(0.0016) \\
\end{array}$ & $\begin{array}{c}0.7553 \\
(0.0028) \\
\end{array}$ \\
\hline & \multirow{3}{*}{0.50} & 0.25 & $\begin{array}{c}0.5019 \\
(0.0046)\end{array}$ & $\begin{array}{c}0.2494 \\
(0.0006)\end{array}$ & $\begin{array}{c}0.5012 \\
(0.0045)\end{array}$ & $\begin{array}{c}0.2481 \\
(0.0004)\end{array}$ & $\begin{array}{c}0.5170 \\
(0.0047)\end{array}$ & $\begin{array}{c}0.2540 \\
(0.0004)\end{array}$ & $\begin{array}{c}0.5035 \\
(0.0040)\end{array}$ & $\begin{array}{c}0.2505 \\
(0.0003) \\
\end{array}$ \\
\hline & & 0.50 & $\begin{array}{c}0.5019 \\
(0.0046)\end{array}$ & $\begin{array}{c}0.4989 \\
(0.0025) \\
\end{array}$ & $\begin{array}{c}0.5012 \\
(0.0045)\end{array}$ & $\begin{array}{c}0.4962 \\
(0.0015) \\
\end{array}$ & $\begin{array}{c}0.5171 \\
(0.0048)\end{array}$ & $\begin{array}{c}0.5081 \\
(0.0016)\end{array}$ & $\begin{array}{c}0.4971 \\
(0.0041)\end{array}$ & $\begin{array}{c}0.4952 \\
(0.0014) \\
\end{array}$ \\
\hline & & 0.75 & $\begin{array}{c}0.5019 \\
(0.0046)\end{array}$ & $\begin{array}{c}0.7483 \\
(0.0055)\end{array}$ & $\begin{array}{c}0.5012 \\
(0.0045)\end{array}$ & $\begin{array}{c}0.7443 \\
(0.0033)\end{array}$ & $\begin{array}{c}0.5170 \\
(0.0048)\end{array}$ & $\begin{array}{c}0.7621 \\
(0.0035)\end{array}$ & $\begin{array}{c}0.4950 \\
(0.0041)\end{array}$ & $\begin{array}{c}0.7398 \\
(0.0032)\end{array}$ \\
\hline & \multirow{3}{*}{0.75} & 0.25 & $\begin{array}{c}0.7548 \\
(0.0078)\end{array}$ & $\begin{array}{c}0.2494 \\
(0.0006)\end{array}$ & $\begin{array}{c}0.7543 \\
(0.0078)\end{array}$ & $\begin{array}{c}0.2481 \\
(0.0004)\end{array}$ & $\begin{array}{c}0.7697 \\
(0.0079)\end{array}$ & $\begin{array}{c}0.2534 \\
(0.0004)\end{array}$ & $\begin{array}{c}0.7486 \\
(0.0071)\end{array}$ & $\begin{array}{c}0.2499 \\
(0.0004)\end{array}$ \\
\hline & & 0.50 & $\begin{array}{c}0.754 \\
(0.0078)\end{array}$ & $\begin{array}{c}0.4989 \\
(0.0025)\end{array}$ & $\begin{array}{c}0.7543 \\
(0.0078)\end{array}$ & $\begin{array}{c}0.4962 \\
(0.0015)\end{array}$ & $\begin{array}{c}0.7697 \\
(0.0079)\end{array}$ & $\begin{array}{c}0.5068 \\
(0.0016)\end{array}$ & $\begin{array}{c}0.7424 \\
(0.0072)\end{array}$ & $\begin{array}{c}0.4938 \\
(0.0014)\end{array}$ \\
\hline & & 0.75 & $\begin{array}{c}0.7548 \\
(0.0078)\end{array}$ & $\begin{array}{c}0.7483 \\
(0.0055)\end{array}$ & $\begin{array}{c}0.7543 \\
(0.0078)\end{array}$ & $\begin{array}{c}0.7443 \\
(0.0033)\end{array}$ & $\begin{array}{c}0.7697 \\
(0.0079)\end{array}$ & $\begin{array}{c}0.7602 \\
(0.0035)\end{array}$ & $\begin{array}{c}0.7403 \\
(0.0073)\end{array}$ & $\begin{array}{c}0.7377 \\
(0.0033)\end{array}$ \\
\hline
\end{tabular}


It is clear from the results that the MSE for the Bayesian estimates of $\alpha$ and $\beta$ using informative prior are smaller than their corresponding MSE of the ML and the MOM estimates. Therefore, it can be concluded that the Bayesian method based on informative priors has provided better estimates of the parameters compared to the ML and MOM method.

\section{Conclusion}

In this paper, Exact extreme value distribution is presented. Some of the statistical properties of the Exact extreme value distribution are studied. moments, maximum likelihood and Bayesian -based on noninformative and informative prior distribution -methods are used to estimate the parameters of the distribution. We find that the Bayesian estimators based on informative prior distributions are the best estimators.

\section{References}

[1] Todorovic, P., On some problems involving random number of random variables, The Annals of Mathematical Statistics, 41(3), 1970, p. 1059-1063.

[2] Todorovic, P. and Zelenhasic, E., A stochastic model for flood analysis, Water Resources Research, 6(6) 1970, p. 1641-1648.

[3] Kotb, N.S.A., El-Gohary, M.M. and El-Helbawy, A.T. , Analysis of Flood Frequency Distribution, Journal of Faculty of Commerce Al-Azhar University Girls Branch, 19,2001, p. 5-25.

[4] Cunnane, C., A note on the Poisson assumption in partial duration series models, Water Resources Research, 15(2), 1979, p. 489494.

[5] Bhunya, P.K., Singh, R.D., Berndtsson, R. and Panda, S.N.,Flood analysis using generalized logistic models in partial duration series,. Journal of hydrology, 420,2012, p. 59-71.

[6] Bezak, N., Brilly, M. and Sraj, M., Comparison between the peaks-over-threshold method and the annual maximum method for flood frequency analysis, Hydrological Sciences Journal, 59(5),2014, p. 959-977. 